\title{
Coronary Angiographic Severity in Patients With Raised Plasma Homocysteine Level
}

\author{
MS Kabir ${ }^{1}$, AAS Majumder ${ }^{2}$, MS Bari ${ }^{1}$, AW Chowdhury², AM Islam ${ }^{3}$ \\ ${ }^{1}$ Department of Cardiology, Dinajpur Medical College. ${ }^{2}$ Department of Cardiology, NICVD \\ ${ }^{3}$ Department of Cardiology, Dhaka Medical college
}

Key words:

Homocysteine,

Coronary

artery disease,

Coronary

angiogram.

\begin{abstract}
:
Background: Besides conventional classic risk factors of ischaemic heart disease other variables that have come under scrutiny for their potential contribution include estrogen deficiency, lipoprotein (a), plasma fibrinogen, plasminogen-activator inhibitor type I, endogenous tissue plasminogen activator (tPA), C-reactive protein and homocysteine. A number of studies have been undertaken worldwide shows strong correlation of raised fasting plasma homocysteine level with the development of atherosclerotic vascular diseases, myocardial infarction or increasing severity of coronary artery diseases.

Objective: To find out the correlation of fasting plama homocysteine level with the severity of coronary artery disease in our population.

Method: We undertook a study involving 100 patients of ischaemic heart disease (determined clinically \& by non-invasive tests) in National Institute of Cardiovascular Diseases, Dhaka, Bangladesh, over the period of one year from January 2003 to December 2003. Out of 100 patients, 50 patients having normal homocysteine level were considered as control and another 50 patients having raised plasma homocysteine level were taken as cases.

Result: Out of 50 patients, $20 \%$ had single vessel disease, $48 \%$ had double vessel disease and $32 \%$ had 3 vessel diseases. On the other hand in control group 10\% patients had normal coronary artery disease, 40\% had single vessel disease, 32\% had double vessel disease and 18\% had triple vessel disease.

Conclusion: The study showed significant increase in number of coronary artery involvement by atherosclerotic lesions with increasing levels of plasma homocysteine level.
\end{abstract}

(Cardiovasc. j. 2009; 1(2) : 169-173)

\section{Introduction:}

Despite steady progress in treatment of cardiovascular diseases, people are still dying of these diseases, although at later ages. ${ }^{1} \mathrm{By}$ the year 2020, Coronary heart disease (CHD) and stroke will hold first and fourth places respectively, in the World Health Organization's list of leading causes of disability. ${ }^{2}$ In recent years, it has been suggested that only one half to two thirds of risk for atherosclerotic vascular disease can be explained by classic risk factors. ${ }^{3}$ Other variables that have come under scrutiny for their potential contribution include estrogen deficiency, lipoprotein (a), plasma fibrinogen, plasminogenactivator inhibitor type I, endogenous tissue plasminogen activator (tPA), C-reactive protein and homocysteine. ${ }^{4}$ There is a growing recognition that high level of homocysteine is associated with heart disease. ${ }^{5}$ According to 1999 science advisory from American Heart Association (AHA) Nutrition Committee, plasma concentrations of fasting homocysteine between 5 and $15 \mu \mathrm{mol} / \mathrm{L}$ are considered normal. Elevated homocysteine levels are referred to as hyperhomocysteinemia moderate, between 16 and $30 \mu \mathrm{mol} / \mathrm{L}$; intermediate, between 31 and $100 \mu \mathrm{mol} / \mathrm{L}$ and severe, higher than $100 \mu \mathrm{mol} / \mathrm{l} .{ }^{6}$ Plasma homocysteine is increasingly recognized as an independent risk factor for vascular disease including coronary artery disease, cerebrovascular disease and peripheral vascular diseases as well as deep venous thrombosis. ${ }^{7}$ Boushey et al suggest that a $1 \mu \mathrm{mol} / \mathrm{L}$ increment in homocysteine concentration is associated with a $10 \%$ increase in coronary artery disease risk. ${ }^{8}$ A positive relationship between homocysteine and risk of myocardial infarction was seen in a large prospective community study from Norway. ${ }^{9}$ Schnyder et al., in their study, showed that tHcy together with age and gender, is a strong predictor of the severity of coronary artery disease ${ }^{10}$. Though works have been done in Bangladesh to evaluate hyperhomocysteinaemia as a risk factor for CHD, no angiographic correlation with total plasma homocysteine level has yet been done to determine severity of CAD in patients with hyperhomocysteinaemia. With this back ground, the present study was undertaken to find out the relationship between plasma total homocysteine

Address of Correspondence: Md. Shahriar kabir, Assistant Professor of Cardiology, Dinajpur Medical College, Dinajpur, Bangladesh 
level (tHcy) with angiographic severity of coronary artery disease (CAD) in patients with ischaemic heart disease in our population.

\section{Study population:}

The study was carried out during the period from January, 2003 to December 2003 in National Institute of Cardiovascular Diseases (NICVD), Dhaka, Bangladesh. A total of 100 patients were included in this study. Amongst them 50 patients were taken as cases (tHcy $>15 \mu \mathrm{mol} / \mathrm{l}$ ) and 50 patients were taken as control $\quad(\mathrm{tHcy}<15 \mu \mathrm{mol} / \mathrm{l})$.

\section{Inclusion Criteria:}

Patients admitted in NICVD for coronary angiography with the diagnosis of ischaemic heart disease documented by clinical characteristic and noninvasive tests.

\section{Exclusion criteria:}

1. Renal dysfunction (serum creatinine $>1.8 \mathrm{mg} / \mathrm{dl}$ )

2. Liver dysfunction

3. Patients with connective tissue disease

\section{Methodology:}

Informed consent was taken from all the patients.Baseline clinical data including clinical history and risk factors was recorded in data sheet.Relevant physical examination was done on all patients.Routine investigations for coronary angiography and serum lipid profile were done in every patient. Fasting blood sample $(3 \mathrm{ml})$ was drawn in every patient undergoing coronary angiography for estimation of total plasma homocysteine by chemi-luminescnce method. Homocysteine level $>15 \mathrm{mmol} / \mathrm{l}$ was regarded as hyperhomocysteinaemia.

Angiogram was reviewed to identify culprit lesions and $>50 \%$ stenosis was regarded as significant. Disease severity was evaluated by counting the major epicardial coronary arteries (left anterior descending, circumflex and right) affected with ${ }^{3} 1$ significant stenosis (>50\%). CAD severity was scored as 0 (normal angiographic vessels), 1 (1vessel disease), 2 (2-vessel disease), or, 3 (3- vessel disease) respectively. Stenosis of a left main-stem artery without stenosis of the right coronary artery was classified as 2 -vessel disease.

\section{Data analysis:}

Data were presented in frequency, percentage and mean and standard deviation as applicable. Comparison between groups was done by student's't' test, chi-square test, Fisher's exact test as applicable. Multivariate analysis was done to determine whether likelihood of coronary artery involvement differed by elevated total homocysteine group. All data were analyzed by using computer based SPSS (Statistical Package for Social Science) program. P value of less than 0.05 was considered as significant.

\section{Results:}

Table-I shows plasma homocysteine level in study and control group. Study group consist of patients having plasma homocysteine $>15$ micro-mol/l and control group $<15$ micro-mol/l. Table-II shows different demographic variables, clinical presentations, risk factors and plasma homocysteine level in study and control group. Median age was 52 and 53 years in study and control group respectively. Most of the patients were male in both groups. Risk factors like smoking, diabetes mellitus, dyslipidaemia and family history of IHD were similar in the two groups. Mean plasma homocysteine levels were 18.26 and 10.84 micro-mol/l in study and control group respectively. Table-III shows correlation of disease severity with different laboratory findings. Blood sugar level and plasma homocysteine level show significant correlation with disease severity. Table-IV showed plasma homocysteine level in patients having other risk factors for IHD and indicates that patients having other risk factors also have increasing levels of homocysteine with increasing severity of coronary artery disease. Figure - 1 showed number of coronary artery involvement with atherosclerotic process in study and control groups. In study group none of the patients had normal coronary arteries. Out of 50 patients, $20 \%$ had single vessel disease, $48 \%$ had double vessel disease and $32 \%$ had 3 vessel diseases. On the other hand in control group 10\% patients had normal coronary artery disease, $40 \%$ had single vessel disease, $32 \%$ had double vessel disease and $18 \%$ had triple vessel disease.

\section{Table-I}

Plasma homocysteine level in study and control groups

\begin{tabular}{lcc}
\hline Group & $\begin{array}{c}\text { Number of } \\
\text { patients }\end{array}$ & $\begin{array}{c}\text { Plasma } \\
\text { homocysteine } \\
\text { level }(\mu \mathrm{mol} / \mathrm{L})\end{array}$ \\
\hline Study & 50 & $8-14$ \\
Control & 50 & $16-25$ \\
\hline
\end{tabular}




\section{Table-II}

Characteristics of patients relating demographic variables, clinical presentation, risk factors and plasma homocysteine level

\begin{tabular}{lcc}
\hline Characteristics & Study group & Control group \\
\hline Median age & 53 years & 52 years \\
Sex : & & \\
Male & $80 \%$ & $74 \%$ \\
Female & $20 \%$ & $26 \%$ \\
BMI $(\mathrm{kg} / \mathrm{m} 2)$ & $* 27.68 \pm 3.33$ & $26.51 \pm 2.90$ \\
Stable angina & $18 \%$ & $7 \%$ \\
Unstable angina & $36 \%$ & $19 \%$ \\
MI & $46 \%$ & $51 \%$ \\
Smoking & $60 \%$ & $66 \%$ \\
Hypertension & $48 \%$ & $48 \%$ \\
Diabetes mellitus & $42 \%$ & $38 \%$ \\
Dyslipidaemia & $36 \%$ & $38 \%$ \\
Family history of IHD & $32 \%$ & $28 \%$ \\
Plasma total homocysteine & $* 18.26 \pm 2.32$ & $10.84 \pm 1.45$ \\
(micro-mol/l) & & \\
\hline
\end{tabular}

*Mean \pm SD

Table-III

Laboratory finding according to number of diseased coronary arteries

\begin{tabular}{|c|c|c|c|c|c|}
\hline \multirow[t]{2}{*}{ Variables* } & \multicolumn{4}{|c|}{ Number of diseased coronary arteries(e" $50 \%$ stenosis) } & \multirow[t]{2}{*}{$p$-value } \\
\hline & $\begin{array}{c}0 \\
(\mathrm{n}=5)\end{array}$ & $\begin{array}{c}1 \\
(\mathrm{n}=30)\end{array}$ & $\begin{array}{c}2 \\
(\mathrm{n}=40)\end{array}$ & $\begin{array}{c}3 \\
(\mathrm{n}=25)\end{array}$ & \\
\hline $\begin{array}{l}\text { Blood sugar } \\
(\mathrm{m} \mathrm{mol} / \mathrm{l})\end{array}$ & $5.9 \pm 0.22$ & $7.35 \pm 1.98$ & $7.58 \pm 2.4$ & $8.06 \pm 2.28$ & 0.01 \\
\hline $\begin{array}{l}\text { serum creatinine } \\
(\mathrm{mg} / \mathrm{dl})\end{array}$ & $0.96 \pm 0.02$ & $0.85 \pm 0.18$ & $0.91 \pm 0.14$ & $0.94 \pm 0.14$ & 0.131 \\
\hline Total cholesterol & $201.0 \pm 14.31$ & $220.16 \pm 44.4$ & $207.75 \pm 43.36$ & $223.0 \pm 60.0$ & 0.493 \\
\hline $\begin{array}{l}\text { HDL cholesterol } \\
(\mathrm{mg} / \mathrm{dl})\end{array}$ & $11.40 \pm 0.54$ & $38.6 \pm 5.7$ & $42.63 \pm 12.80$ & $39.0 \pm 5.95$ & 0.252 \\
\hline $\begin{array}{l}\text { LDL cholesterol } \\
(\mathrm{mg} / \mathrm{dl})\end{array}$ & $96.00 \pm 4.18$ & $120.76 \pm 35.8$ & $115.63 \pm 36.9$ & $128.6 \pm 44.03$ & 0.285 \\
\hline $\begin{array}{l}\text { Serum triglyceride } \\
(\mathrm{mg} / \mathrm{dl}) \\
\text { Plasma total }\end{array}$ & $183.0 \pm 13.96$ & $217.0 \pm 64.1$ & $207.37 \pm 58.6$ & $213.2 \pm 57.5$ & 0.66 \\
\hline $\begin{array}{l}\text { homocysteine } \\
(\mu \mathrm{mol} / \mathrm{l})\end{array}$ & $10.6 \pm 1.82$ & $12.67 \pm 2.67$ & $14.54 \pm 3.76$ & $17.62 \pm 4.82$ & 0.001 \\
\hline
\end{tabular}

*Variables are mean \pm SD 
Table-IV

Plasma homocysteine levels according to cardiovascular risk factors and the number of diseased coronary arteries

\begin{tabular}{lccccc}
\hline Variables & \multicolumn{2}{c}{ Plasma homocysteine level $(\mu \mathrm{mol} / \mathrm{L})$ in CAD of different severity } & \multirow{2}{*}{$p$-value } \\
\cline { 2 - 5 } & $\begin{array}{c}\text { Vessel } \\
\text { score-0 }\end{array}$ & $\begin{array}{c}\text { Vessel } \\
\text { score-1 }\end{array}$ & $\begin{array}{c}\text { Vessel } \\
\text { score-2 }\end{array}$ & $\begin{array}{c}\text { Vessel } \\
\text { score-3 }\end{array}$ & \\
\hline Smoking $(\mathrm{n}=63)$ & $11.0 \pm 1.3$ & $12.26 \pm 2.5$ & $143.6 \pm 3.71$ & $17.06 \pm 5.41$ & 0.006 \\
Hypertension (n=48) & $9.67 \pm 1.5$ & $13.0 \pm 2.77$ & $15.15 \pm 3.7$ & $16.0 \pm 4.98$ & 0.032 \\
Diabetes (n=40) & 0 & $13.64 \pm 2.5$ & $14.88 \pm 3.56$ & $16.0 \pm 5.5$ & 0.393 \\
Hypercholesterolaemia & $9.67 \pm 1.5$ & $13.67 \pm 2.7$ & $14.31 \pm 3.7$ & $15.19 \pm 4.5$ & 0.122 \\
Cholesterol $\geq 200 \mathrm{mg} / \mathrm{dl}$ & & & & & \\
(n=47) & & & & & \\
All Patients (n=100) & $10.6 \pm 1.8$ & $12.7 \pm 2.7$ & $14.54 \pm 3.8$ & $17.62 \pm 4.8$ & 0.001 \\
\hline
\end{tabular}

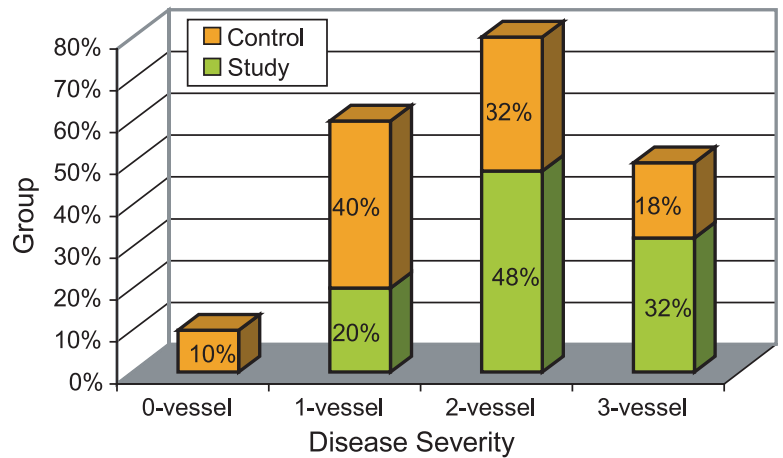

Fig. 1: Distribution of patients in percentage by vessel score

\section{Discussion:}

This prospective observational study involved 100 patients and was conducted in NICVD, Bangladesh. 50 patients were taken as control who had normal plasma homocysteine level and 50 patients were taken as study group having plasma homocysteine level above 15 ì mol/l. Hypertension, diabetes mellitus, dyslipidaemia, smoking and family history of IHD were considered as major risk factors in both study and control group. Any patient admitted in NICVD for coronary angiography with a diagnosis of IHD was considered as study subject. Fasting plasma homocysteine level was done in all patients. Finally coronary angiography was done and it was evaluated for the number of major epicardial coronary arteries severely narrowed (e" $50 \%$ stenosis).

Demographic variables and risk factors like smoking, diabetes mellitus, dyslipidaemia and family history of premature atherosclerotic vascular diseases are similarly distributed in both study and control groups. In this study, mean fasting plasma homocysteine level was $14.55 \pm 4.19$ ì $\mathrm{mol} / \mathrm{l}$ with a minimum of $8.00 \mu \mathrm{mol} / \mathrm{l}$ in control group and maximum of $25.00 \mathrm{i} \mathrm{mol} / \mathrm{l}$ in study group. It is well evident from this study that the number of vessel involvement with atherosclerotic process increased significantly with the increase of tHcy level $(p<0.05)$. For vessel score- 1 tHcy was 10.60 \pm 1.81 ; and for vessel score-3 tHcy was $17.62 \pm$ $4.80 \mu \mathrm{mol} / \mathrm{l}$. The number of major epicardial coronary arteries severely narrowed (>50\% stenosis) is significantly higher in study group compared to control group ( $\mathrm{p}<0.05)$.

The result of our study is consistent with another study on this topic done by Schnyder et al in 2001 which also showed significant association of tHcy with the severity of CAD $(p<0.05) .{ }^{10}$ In their study tHcy was $9.1 \pm 3.2 \mu \mathrm{mol} / \mathrm{l}$ in the group with 0 vessel disease. With increasing severity of CAD, tHcy levels increased significantly to $12.4 \pm 5.4 \mu$ $\mathrm{mol} / \mathrm{l}$ in patients with 3 -vessel disease. Our study also shows significant association of tHcy with the severity of CAD. In this study tHcy levels were $10.60 \pm 1.82$ in the group with 0 -vessel disease and $17.62 \pm 4.8$ in the group with 3 -vessel disease. The current study differs largely from that conducted by Schnyder et al by number of patients (631 patients were studied by Schynder et al; whereas 100 patients were included in our study.)

Despite having similar distribution of cardiovascular risk factors in cases and control 
groups, increasing severity of $\mathrm{CAD}$ was associated with higher levels of tHcy, which reflects an independent association of tHcy with CAD severity. This finding is consistent with studies undertaken by others like Boushey et al (1995), zaher et al (2003) and Dey A (2002). 8, 11, 12

Obeid et al undertook two parallel case-control studies; one in Europeans and one in Indian Asians. ${ }^{13}$ Fasting plasma homocysteine concentration was $8 \%$ higher in cases compared to control in both ethnic groups. The odds ratio of CHD for a 5 micro mol/l increment in tHcy was 1.3 in Europeans and 1.2 in Indian Asians. The association between tHcy and CHD was independent of conventional CHD risk factors in both ethnic groups. Our study is consistent with this finding.

Boushey et al undertook several studies to determine the contribution of tHcy to CAD, cerebrovascular diseases and peripheral vascular diseases. The odds ratio for CAD of a 5 micro mol/ 1 tHcy increment was 1.6 (95\% CI 1.4 to 1.7 ) for men and 1.8 for women (95\% CI 1.3 to 1.9$).{ }^{8}$ Our study also showed significant association of plasma homocysteine with the development of severe coronary artery disease.

Zaher et al conducted a study on 233 patients in 2003 to determine the contribution of tHcy to CAD. The study concluded with the finding of independent association of raised tHcy with increased risk of having CAD. Our study showed progressive increase in severity of $\mathrm{CAD}$ with the increasing levels of tHcy. ${ }^{11}$

A related study was undertaken in NICVD, Dhaka, Bangladesh, during the period of November 2001 to May 2002 to determine the likelihood association of raised tHcy with acute myocardial infarction. The study enrolled 70 patients with acute MI as cases and a control involving 70 persons without IHD. Cases had a higher tHcy level (15.8 \pm 7.9 micro $\mathrm{mol} / \mathrm{l})$ than that of control $(10.4 \pm 3.5 \mathrm{micro} \mathrm{mol} / \mathrm{l})$. The study concluded with an inference indicating tHcy as an independent risk factor for IHD. ${ }^{12}$ The inference is consistent with the results of our study.

\section{Conclusion:}

Raised plasma total homocysteine level seems to have a significant positive correlation with angiographic severity of coronary artery disease.
It may also be regarded as an independent risk factor for ischaemic heart disease. Raised plasma total homocysteine level may thus predict whether early interventional or a more comprehensive approach of therapy would provide maximum benefit to the patients. However, further studies involving a large number of participants will be required to substantiate the findings of the current study.

\section{References:}

1. Fuster V. Epidemic of cardiovascular disease and stroke: The three main Challenges. Circulation1999; 99:113237.

2. Murray C J, Lopez AD. Mortality by cause for eight regions of the world: Global burden of disease study. Lancet1997; 349:1269-76.

3. Eikelboom JW, Lonn E, Genest J.Jr et al. Homocysteine and cardiovascular disease: A critical review of the epidemiologic evidence. Ann Intern Med 1999; 131: 363375 .

4. Braunwald E, Shattunck. Cardiovascular medicine at the turn of the millennium: triumphs, cancers and opportunities. N Eng J Med 1997; 337:1360-1369.

5. McCully K. Pioneer of the homocysteine theory. Lancet 1998; 352:1364.

6. Hankey JH, Eikelboom JW. Homocysteine and vascular disease. Lancet 1999; 354: 407-13.

7. Malinow MR, Boston AG, Krauss RM. Homocysteine, diet and cardiovascular disease: A statement for health care professionals from the nutrition Committee. American Heart Association. Circulation 1999; 99: 17882.

8. Boushey CJ, Beresford SAA, Omen GS, et al. A quantitative assessment of plasma homocysteine as risk factors for vascular diseases: Probable benefits of increasing folic acid intakes. JAMA1995; 274:1049-1057.

9. Arnesen, E., Refsum, H., Bonaa, K.H., et al., 1995. Serum total homocysteine and coronary heart disease. Int $J$ Epidemiol; vol. 24: pp.704-709.

10. 10. Schnyder G, Pin R, Roffi M, et al. Association of plasma homocysteine with the number of major coronary arteries severely narrowed. Am J Cardiol 2001; 88: 1027 - 1030.

11. 11. Zaher A., Majumder A A S, Mohibullah A K M, et al. Homocysteine as a risk factor for coronary artery disease in Bangladeshi population. Bangladesh Heart journal 2003; 18: 1; 3-7. 2003.

12. Dey A. 2002. Plasma homocysteine level as a risk factor for acute myocardial infarction, MD theses, National Institute of Cardiovascular Diseases, Dhaka.

13. Obeid, O. A., Mannan, N., Perry. G. et al., 1998. Homocysteine and folate in healthy east London Bangladeshis. Lancet; vol. 352: pp.1829-30. 